\title{
Extraction of BTX Hydrocarbons from Saudi Arabian Refinery Platformates
}

\author{
A.H. Zahed, Y. Yorulmaz and M.A. Gashghari \\ Chemical Engineering Department, Faculty of Engineering, \\ King Abdulaziz University, Jeddah, Saudi Arabia.
}

\begin{abstract}
The recovery of benzene, toluene and xylene isomers, commonly known as BTX, from catalytically reformed naphthas of three different Saudi Arabian refineries was studied by using liquid-liquid extraction in a single batch process. The effects of temperature, solvent to feed ratio, and feed composition on yield and selectivity were investigated with two solvents, namely sulfolane and diethylene glycol. A comparison among the platformates of the three different refineries in terms of yield, has shown that the Petromin-Shell Refinery in Al-Jubail has the most suitable naphtha for the extraction of BTX aromatics.
\end{abstract}

\section{Introduction}

The light aromatics that were studied in this work, i.e. benzene, toluene and xylenes are considered as back bones for the manufacture of many petrochemical products. Further information on their importance and versatility can be found in the literature $^{[1-3\}}$. BTX hydrocarbons are present in straight run petroleum fractions in small quantities. For instance, the benzene, toluene, and xylene content of most straightrun gasolines of end point $150^{\circ} \mathrm{C}$ does not total more than $10-12$ percent. Some crudes, however, contain up to 6 percent aromatics. Naphthenes, on the other hand, are present in many gasolines to the extent of 50 weight percent ${ }^{41}$.

Straight separation of aromatics from petroleum is not recommended as an attractive proposition because of their low concentrations which result in low yield. In addition, the difficulty of separating them from napthenes of similar boiling range 
poses another problem. Most of the processes for the production of aromatics from petroleum, therefore, include methods of converting naphthenes and paraffins to aromatics first with dehydrogenation processes generally called catalytic reforming ${ }^{[5]}$. Most recent catalytic reformers employ platinum containing catalysts; a nonregenerative process is called platforming, while a regenerative one is called ultraforming ${ }^{[6]}$. The earliest large scale process used to separate BTX from non-aromatics was straight distillation, since a large number of homogeneous binary azeotropes exist between aliphatic and aromatic hydrocarbons ${ }^{[7,8]}$. This results in a great deal of benzene being lost in light ends. The recovery of pure aromatics is also prevented by their low relative volatilities compared with those of several aliphatics.

Silica gel can seletively adsorb aromatics from hydrocarbons mixtures by a process known commercially as Arosorb Process ${ }^{[9]}$. However, this process is of little significance today. In the 1940's, phenol was used as a suitable solvent for increasing benzene recovery and purity in extractive distillation ${ }^{[0]}$. Phenol also proved to be suitable for extractive distillation of toluene, while cresol was preferred for xylene. In the early 1950's, the Udex (Universal Diethylene Glycol) extraction process came into commercial existence and began to take over the separation problem of aromatics. The Udex process in which a liquid-liquid extraction of aromatics with diethylene glycol as solvent takes place, was originated by the Dow Chemical Company and later, its licensing was handled by the Universal Oil Products Company ${ }^{[1]}$.

The sulfur dioxide extraction, a process also known as Edeleanu Process, is applied to a wide variety of feed stocks at variable operating temperatures ${ }^{[21}$. The solvent recovery techniques for this process were sufficiently advanced to permit a wide use of this method[13]. In 1959, the Shell Development Company tested a new solvent, sulfolane, as a substitute for diethylene glycol. Bench scale and pilot plant data have indicated its superiority over DEG ${ }^{[14]}$. This process is licensed worldwide by the Universal Oil Products Company (U.O.P.). Diethylene glycol can be used as a solvent in the extractive distillation of mixed alcohols with low carbon content ${ }^{[15]}$. Addition of diethylene glycol to other solvents like ethylene glycol or $N$-methylpyrrolidone increases the extraction capacity, but decreases/or increases selectivity depending on its amount ${ }^{[16]}$. Recovery of high purity aromatics using $N$-formylmorpholine had been studied in India, and found that this new process technology proved to be more economical ${ }^{[17]}$

Present separation methods for recovery of aromatics from hydrocarbon streams use liquid-liquid extraction, and most of the processes in the United States refineries use either polyglycols or sulfolane as the extracting solvent ${ }^{[18]}$. In this study, the yield and selectivity of a relatively new solvent, sulfolane, were compared with those of DEG. To achieve our objectives, catalytically upgraded platformates from Petromin Refinery in Jeddah, Petromin Refinery in Riyadh and Petromin-Shell Refinery in Al-Jubail in Saudi Arabia, were used as feed stocks in the experiments.

\section{Experimental System}

Extraction operations were carried out in a single stage batch apparatus of a Corn- 
ing vacuum rotary evaporator type $349 / 2^{[19]}$. Mixing of $500 \mathrm{ml}$ of sample was carried out in a 1-liter round-bottom glass flask of the rotavapor which had an adjustable speed range between 50 to $150 \mathrm{rpm}$. For heating purposes, the rotating flask was immersed in an oil bath, heated to a desired temperature. The apparatus is shown in Fig. 1.

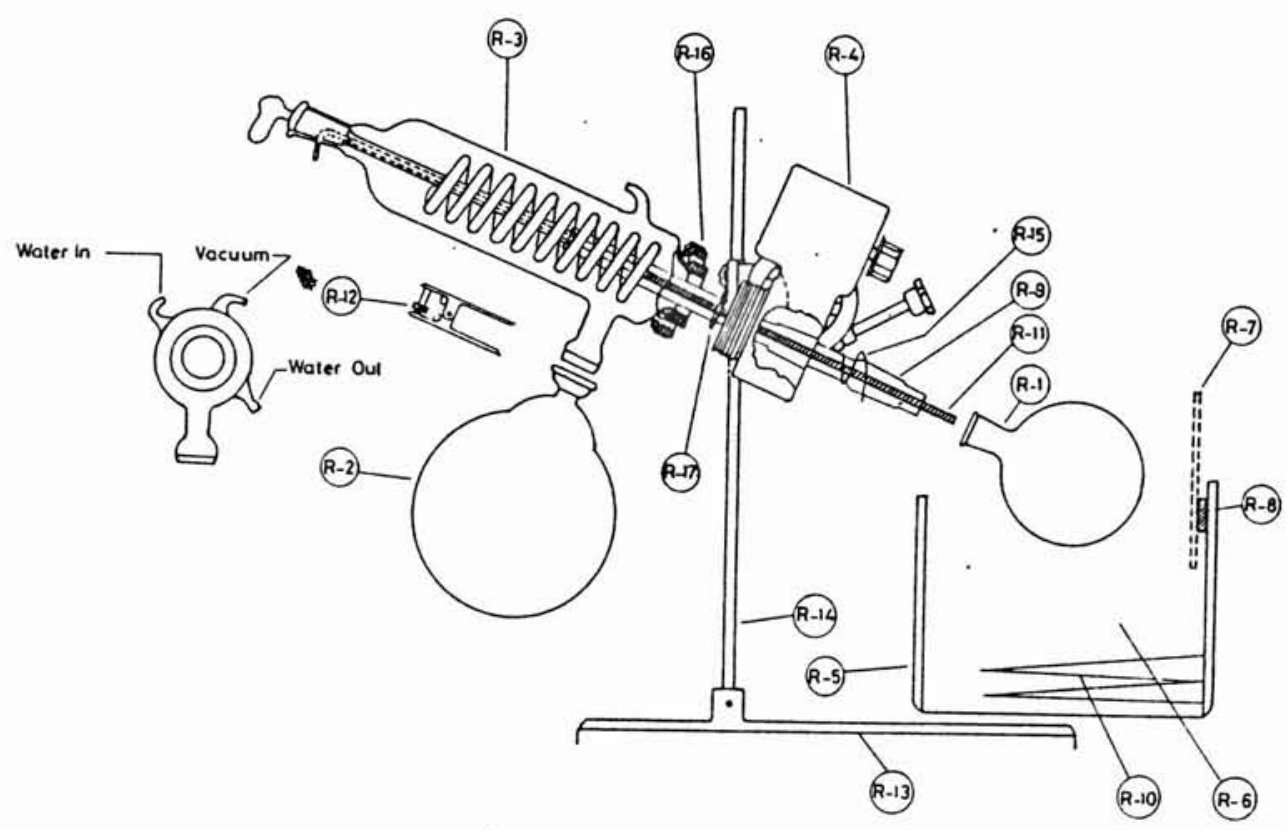

R-1: Rotating retort, $\mathbf{R}-2$ : Receiving vessel. $R-3$ : Condensing unit, $\mathbf{R}-4$ : Motor and gear unit, $R-5$ : Constant temperature bath, $R-6$ : Heating medium (oil), $R-7$ : Contact thermometer, R - 8: Automatic controller, R - 9: Long steam duct with 24/40 or 29/42, R - 10: Heating wires, $R$ - 11: Inlet feed tube, $R-12$ : No. 35 ball joint clamp, $R-13$ : Base, $R-14$ : Stainless steel support rod, $R-15$ : Spring clip for taper joint, $R-16$ : Flanged screw cap, R - 17: GACO gasket seal.

FIG. 1. Rotavapor.

The separation of solvent-phase, upon mixing and extraction, was carried out with a separatory funnel. The aromatics were recovered from the separated solvent layer (extract) by distillation in the rotavapor, which was connected to a vacuum pump for vacuum distillation ( $50.81 \mathrm{~K}$ pascal of vacuum). Since aromatics were the lower boiling compounds, having lower densities than the solvent used, they were boiled away rather easily and a water-cooled condenser was used to condense the aromatics' vapors in liquid form which, in turn, were collected in another receiver flask. Distillation was carried out at temperatures at least $25^{\circ} \mathrm{C}$ above the highest boiling point component in order to ensure that there was no trap of any hydrocarbons in the solvent-rich phase. Due to the wide gap between distillation temperature and solvent boiling 
points (at least $100^{\circ} \mathrm{C}$ ), no traces of solvent were found in the condensate of distilled aromatics.

The physical and chemical compositions of the platformates which are used as raw materials and the analysis of their aromatic contents are given in Table 1. The gas chromatograph employed for the analysis was a Hewlett-Packard 5840-A model. It had a molecular sieve column with a thermal conductivity detector. Helium was used as the carrier gas. Calibration curves for the components to be analysed had to be prepared prior to any quantitative analysis of samples obtained from extraction experiments. The internal standardization method was used in the preparation of calibration curves. For this reason iso-octane was chosen as the standard substance and the yield values contained up to $25 \%$ iso-octane, even though they were solvent free. Solutions with different compositions of aromatics and iso-octane were prepared, and gas-chromatographed.

TABLE 1. Properties of platformates from different Saudi Arabian Refineries and their analysis.

\begin{tabular}{|l|c|c|c|}
\hline \multicolumn{1}{|c|}{ Properties } & $\begin{array}{c}\text { Jeddah oil } \\
\text { refinery } \\
\text { platformate }\end{array}$ & $\begin{array}{c}\text { Petromin - Shell } \\
\text { oil refinery } \\
\text { platformate }\end{array}$ & $\begin{array}{c}\text { Riyadh oil } \\
\text { refinery } \\
\text { platformate }\end{array}$ \\
\hline API at $60^{\circ} \mathrm{F}\left(15.5^{\circ} \mathrm{C}\right)$ & 53.39 & $*$ & 47.23 \\
RVP K pascal & 51.03 & $*$ & 39.31 \\
Distillation, ASTM $@ 760 \mathrm{~mm}$ & & & 47 \\
Initial boiling point IBP $\quad 10 \%$ & $42^{\circ} \mathrm{C}$ & 45 & 80 \\
\multicolumn{1}{|c|}{$90 \%$} & $62^{\circ} \mathrm{C}$ & 60 & 122 \\
Final boiling point FBP & $122^{\circ} \mathrm{C}$ & 117 & 168 \\
Research octane no. & $160^{\circ} \mathrm{C}$ & 147 & 208 \\
Aromatic component $(\% \mathrm{wt})$ & 89.4 & 174 & 91.3 \\
Benzene & 3.02 & $*$ & 5.75 \\
Toluene & $14.3 \mathrm{C}$ & 8.55 & 13.75 \\
$p \& m-x y l e n e$ & 16.10 & 25.66 & 12.50 \\
$o$-xylene & 3.97 & 22.32 & 3.86 \\
Total BTX & 37.40 & 6.5 & 35.86 \\
\hline
\end{tabular}

* Concerning information was not available.

For the extraction operations, several batches with different compositions of a particular platformate and DEG or sulfolane were prepared and mixed for 12-13 hours. Then they were transferred into a separatory funnel for complete separation of layers. The two layers were the solvent-rich aromatics containing phase, and the upper layer, the praffin-rich, solvent-free raffinate. The aromatics were then distilled off the solvent layers with the rotavapor and collected as condensate for the gas chromatographic analysis. The general flow diagram of these experiments are shown in Fig. 2. Extraction operations were carried out for 5 different solvent to feed ratios at 3 different temperatures using both DEG and sulfolane as solvents. 


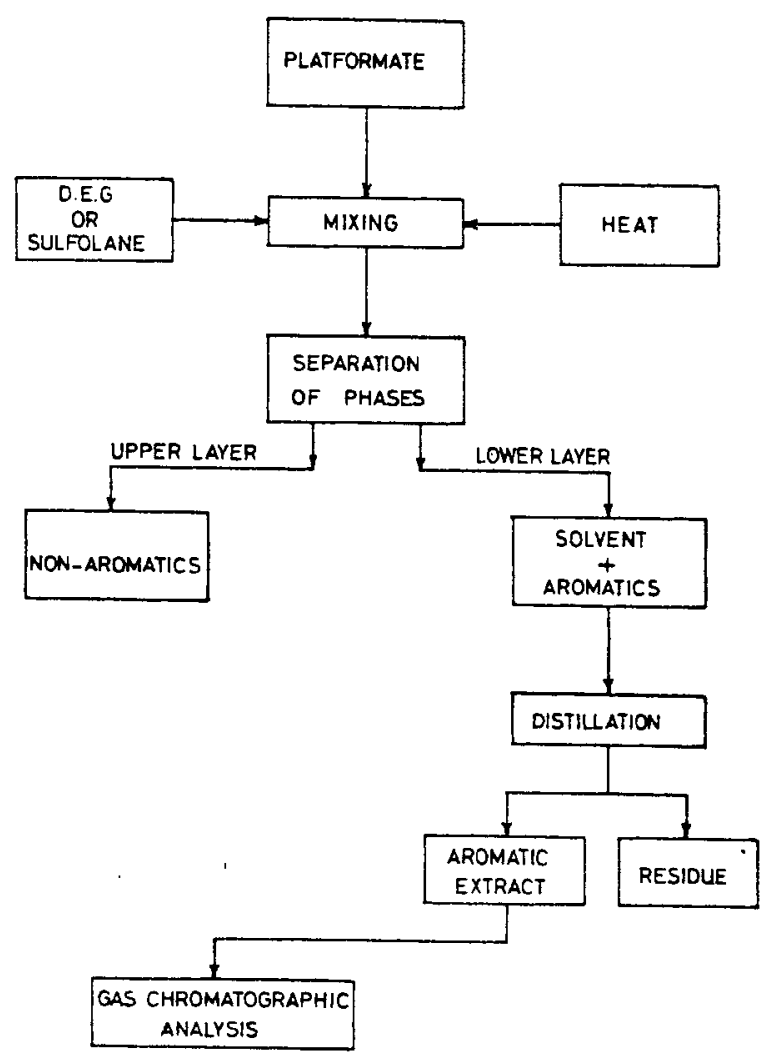

FIG. 2. General flow sheet of experiments.

\section{Results and Discussion}

The total aromatic contents of the three different platformates studied in this work lie between 35 and 63 percent, as shown in Table 1 . The obtained gas-chromatographic results were in good agreement with those supplied by the refineries. The aromatic-rich solvent phase is commonly known as the extract, and its weight is directly proportional to the yield.

The percentage yield values are plotted against temperature with the solvent to feed ratio as a parameter in Fig. 3 and 4 for diethylene glycol and sulfolane, respectively. In both of these figures, it can be seen that for a constant solvent to feed ratio the yield at first increases slowly with temperature. This is followed by a rapid increase at higher temperatures. The increase in the slopes of these curves is more enhanced at higher solvent to feed ratios. A comparison of the yield obtained for diethylene glycol and sulfolane shows that for the same operating conditions sulfolane gives higher yields than DEG. This is due to the fact that aromatics are more soluble in sulfolane than in DEG, as has been mentioned in literature ${ }^{[14]}$. 


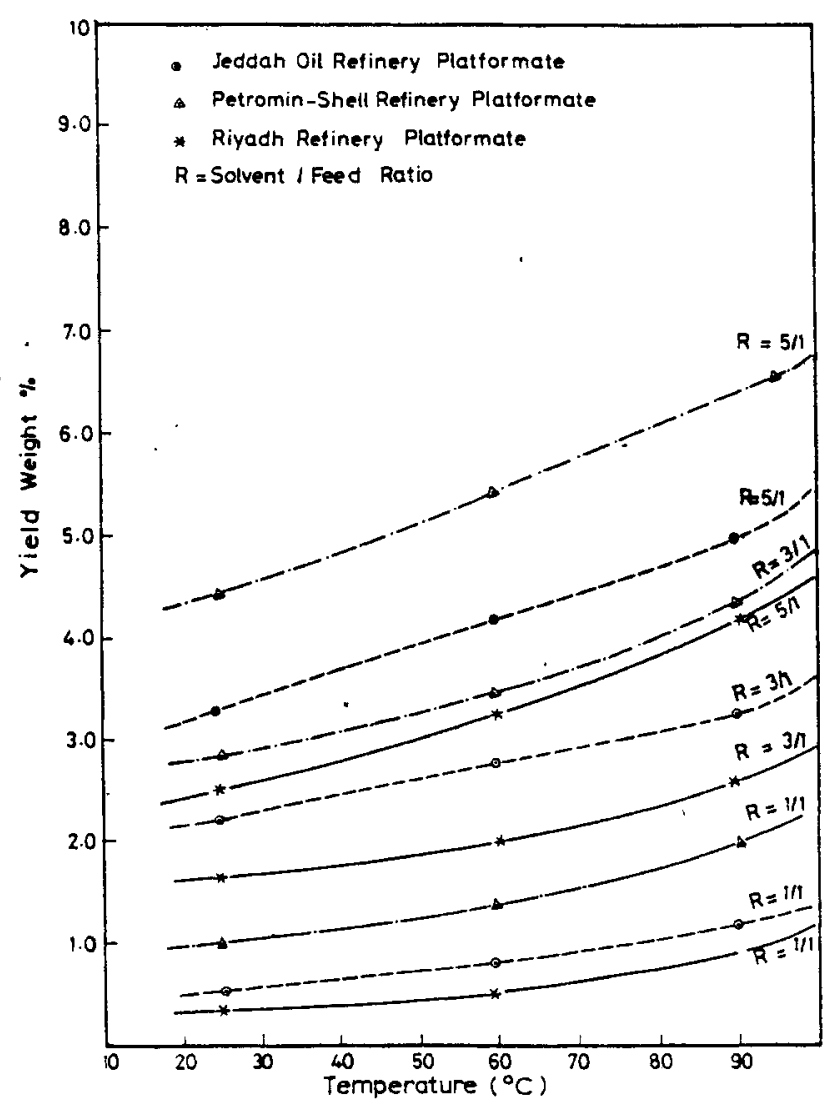

FIG. 3. Yield versus temperature for different platformate samples using diethylene glycol.

The total aromatics percentages in the solvent-free extract products are plotted as a function of extraction temperature at constant solvent to feed ratios for both solvents in Fig. 5-7, for three refinery platformates. If the extract purity is defined as the total percentage of aromatics in the solvent-free extract, then the highest purity is obtained when the solvent to feed ratio is unity. This observation is true for both DEG and sulfolane solvents. Figures 8-10 show purity as a function of solvent to feed ratio at constant temperature for the same three refinery platformates. Again it is seen that the highest purity corresponds to the lowest extraction temperature of $25^{\circ} \mathrm{C}$ for both solvents.

Another observation that can be made from Fig. 5-10 is that diethylene glycol solvent always gives higher purity than sulfolane. This observation is in contrast to the fact that sulfolane always gave higher aromatics yield than diethylene glycol, and that yield increased with temperature and solvent to feed ratio. Therefore, it can be clearly stated that increasing the solvent to feed ratio and/or temperature decreases the extract purity even though it increases the total aromatics yield. In other words, 


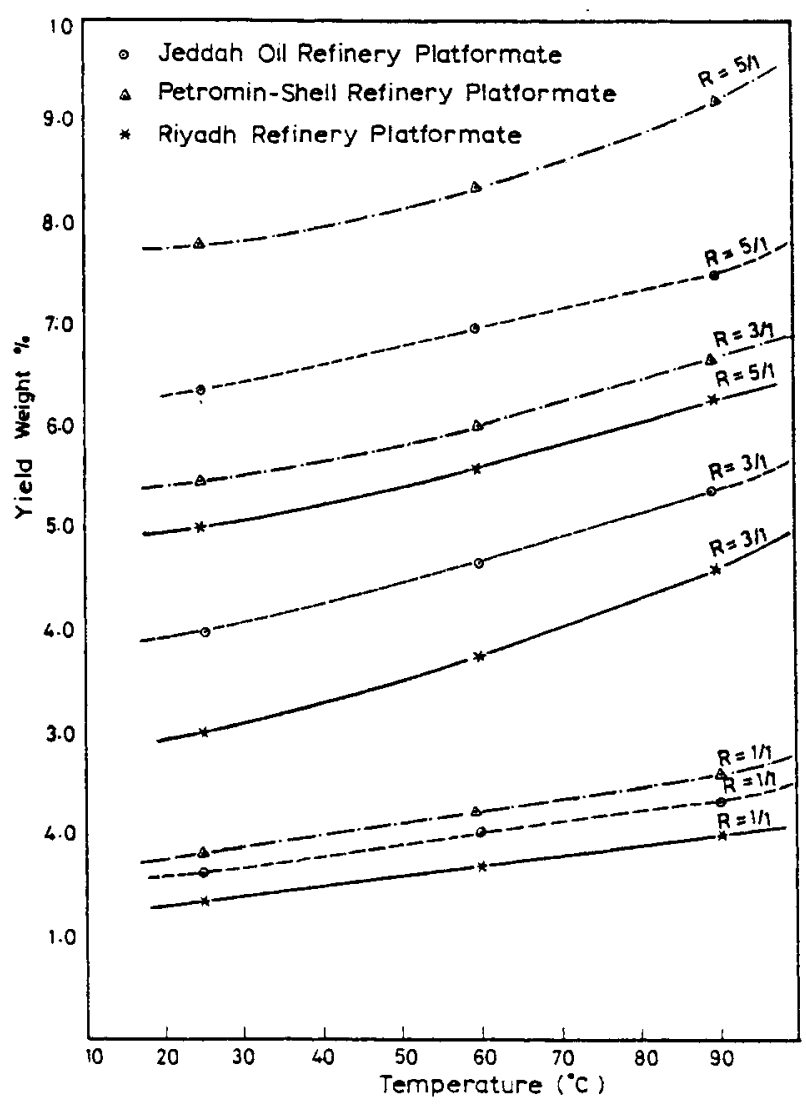

FiG. 4. Yield versus temperature for different platformate samples using sulfolane.

although the weight of extract increases with increasing temperature and/or solvent to feed ratio, the percentage of aromatics in the extract falls down due to the entry of non-aromatics into the extract products. This is because the increase in the temperature and/or solvent to feed ratio increases the solubility of non-aromatic hydrocarbons. This phenomenon is commonly known as selectivity. Thus, the most important criteria for an effective extraction operation is that the extract phase should be large and have high aromatics purity. These criteria can be met by searching for the optimum operating conditions. When the selectivity of sulfolane was compared with that of diethylene glycol, it was observed that diethylene glycol was superior to sulfolane at all temperatures at which experiments were performed.

In Fig. 11, values of the total aromatics percentage in the extract products were plotted versus percentage yield for the three different refinery platformates. From this figure, it is seen that the Petromin-Shell Refinery platformate gives the highest aromatic purity in addition to the highest yields. As for the other two, although the Jeddah Refinery platformate gives higher yields than that of the Riyadh Refinery, its 


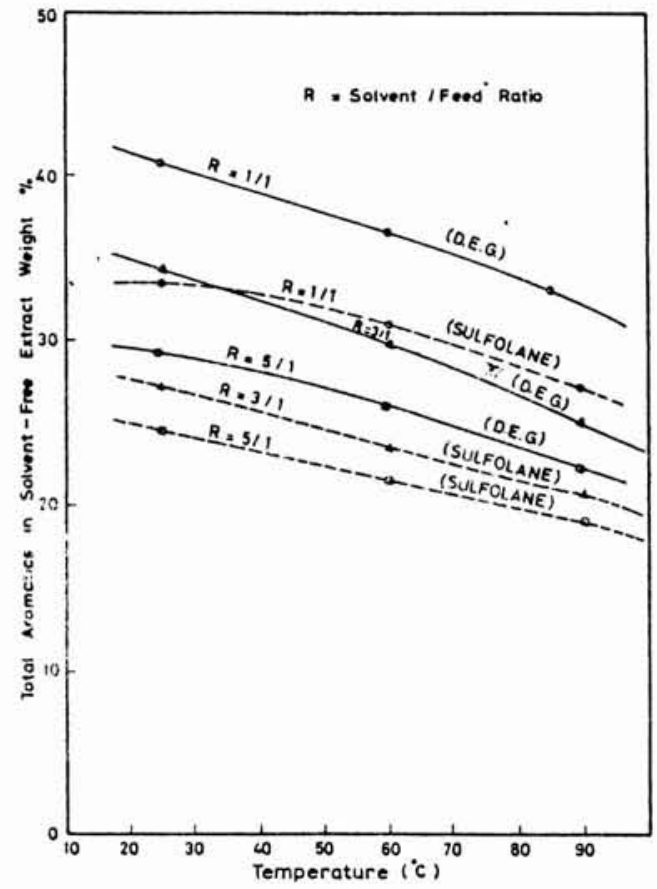

FIG. 5. Total aromatics in solvent-free extract versus temperature (Jeddah Oil Refinery Platformate).

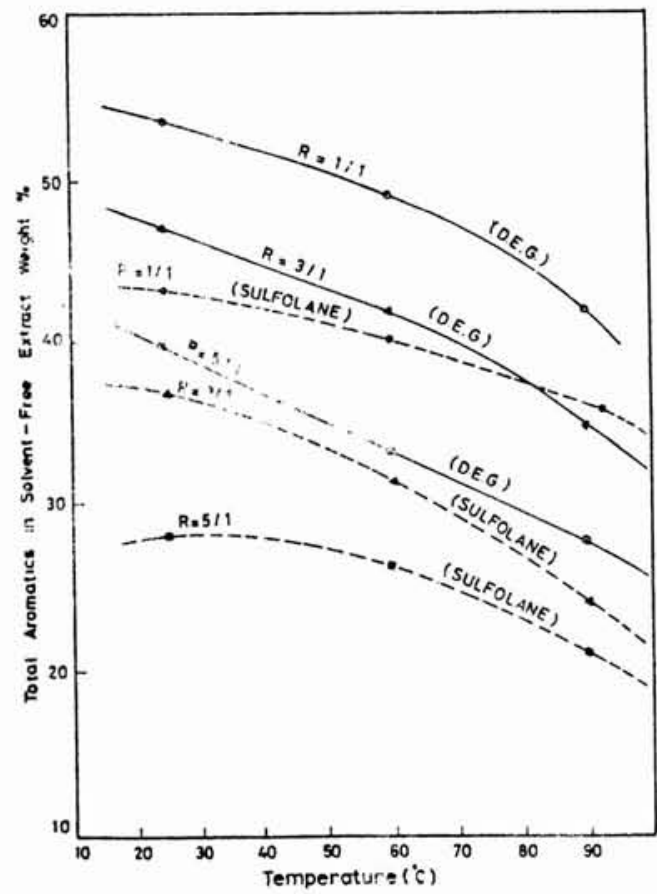

FIG. 6. Total aromatics in solvent-free extract versus temperature (Petromin-Shell Refinery Platformate). 


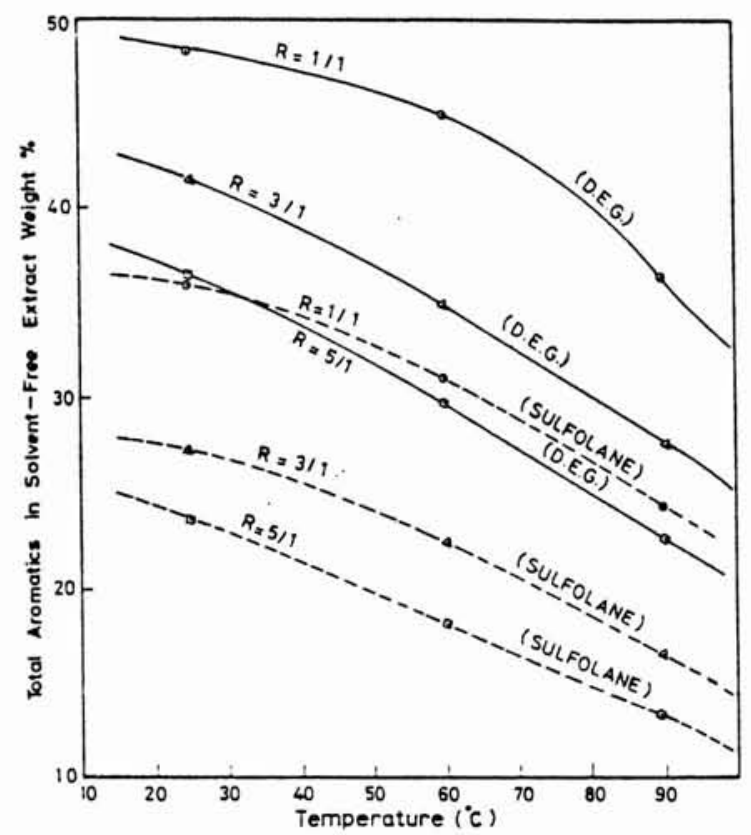

Fig. 7. Total aromatics in solvent-free extract versus temperature (Riyadh Refinery Platformate).

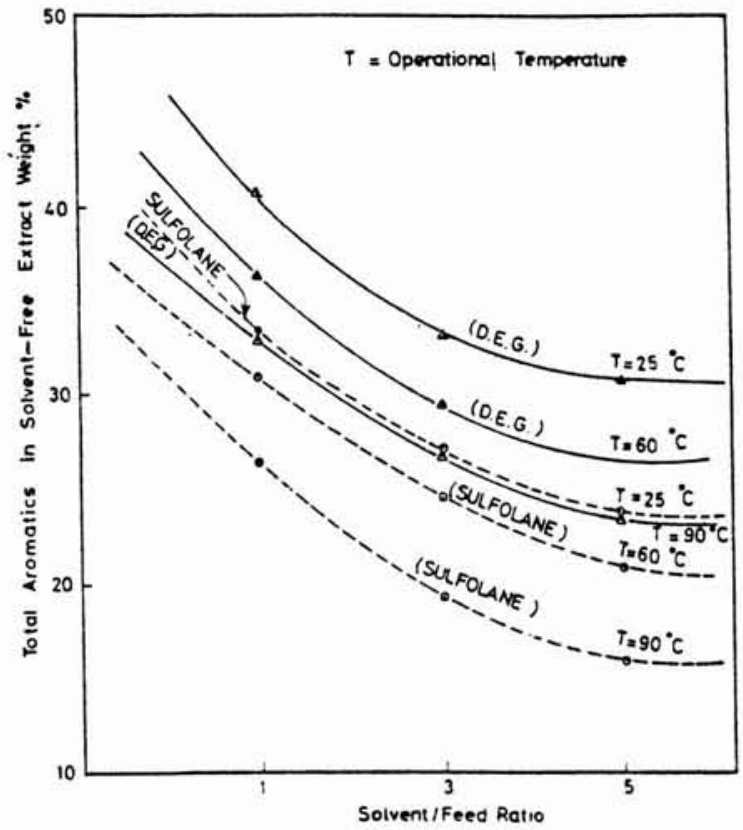

FIG. 8. Total aromatics in solvent-free extract versus solvent/feed ratio (Jeddah Oil Refinery Platformate). 


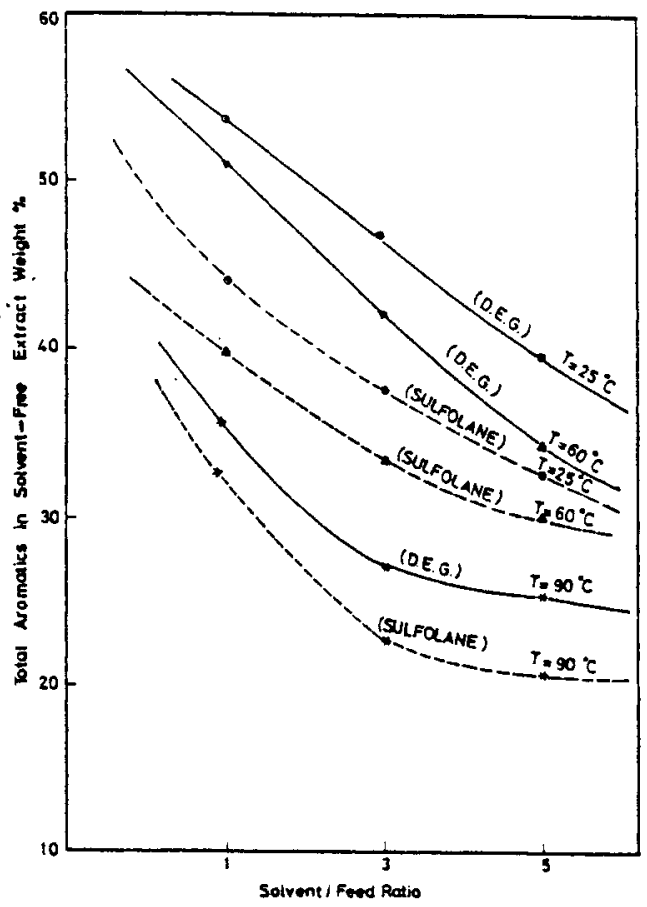

FIG. 9. Total aromatics in solvent-free extract versus solvent/feed ratio (Petromin-Shell Refinery Platformate).

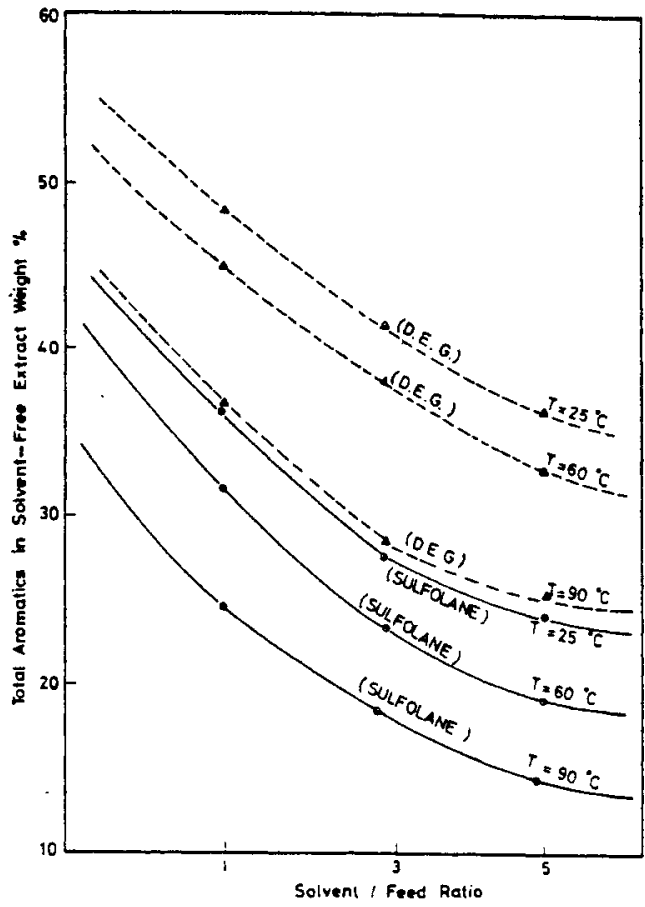

FIG. 10. Total aromatics in solvent-free extract versus solvent/feed ratio (Riyadh Refinery Platformate). 


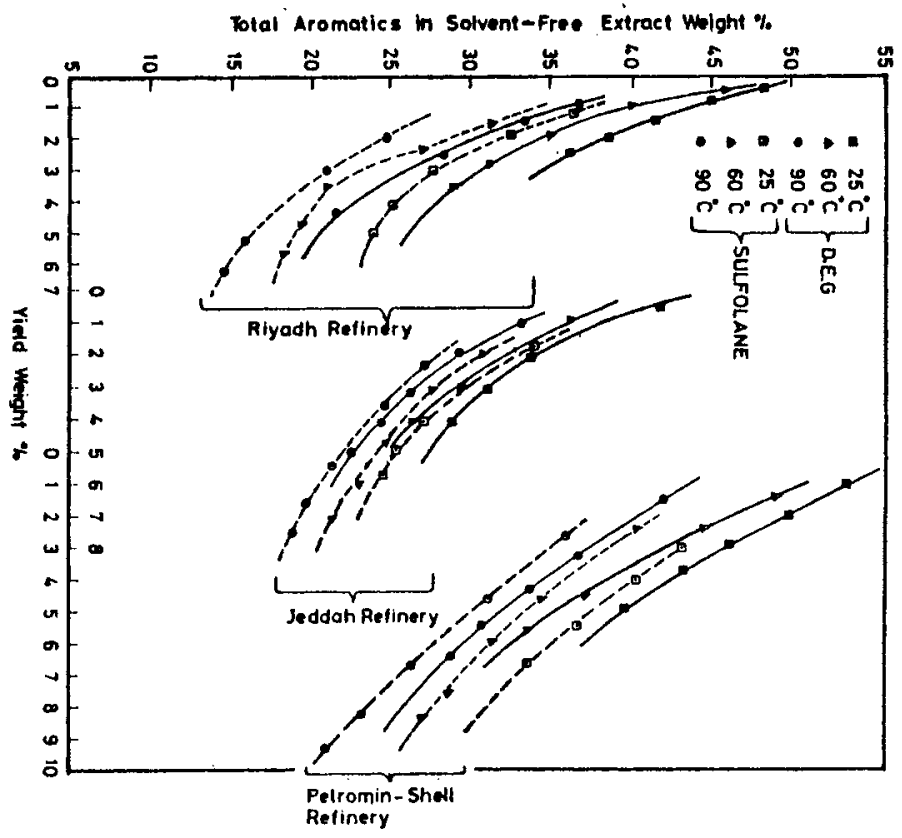

FIG. 11. Total aromatics in solvent-free extract versus yield of different platformates.

extract purity is less than Riyadh's Refinery. This can be explained in the following way: although the Jeddah Refinery platformate originally has a higher total aromatics content, its lighter aromatics contents, benzene and toluene, are lower than those of the Riyadh Refinery platformate. The solubilities of benzene and toluene in both solvents are high and hence they are more easily recovered than meta-, paraand ortho-xylenes during the extraction operations.

Solvent capacity, which is defined as the ratio of the aromatics concentration in the solvent to the one in the raffinate phase, can also pay an equally important role in the choice of solvent. Experimental results in this work have shown that sulfolane has lower selectivity and higher capacity than diethylene glycol. In literature, it has also been confirmed that most solvents with high capacity have low selectivity and vice versa $^{[20]}$. In addition, economic evaluations have proven that solvent capacity has a much greater influence on the cost of production than does solvent selectivity. Because of its high melting point, ambient operational temperatures were observed to be less conducive for the miscibility of sulfolane with platformate than that of DEG.

\section{Conclusion}

The experimental results have shown that the extraction temperature and solvent to feed ratio affect both the yield and selectivity in contrasting manners. Increasing these variables have resulted in increase in the yields while the extract purities and thus the selectivities of the solvents have decreased. The higher yields are usually obtained at the expense of the operation economics as the cost of solvents and subsequent solvent operations increase. High solvent/feed ratios also resulted in better selectivity of lighter BTX aromatics, i.e., benzene and toluene. 
For the two solvents used in this study, sulfolane always had higher solubilities for hydrocarbons than diethylene glycol, as demonstrated by the higher yields obtained. While the selectivity of sulfolane was higher for certain feed mixtures with a higher benzene and toluene content, the diethylene glycol had higher selectivity for other mixtures having a higher xylene isomers content.

The total BTX aromatics content in catalytically reformed naphthas industrially used for aromatics extraction, are in the range of $40-65 \%$. Hence, the Petromin-Shell Refinery platformate with $63 \%$ BFX aromatics is the most suitable for this purpose.

Considering yield and selectivity, pressure requirement due to hydrocarbon volatilities at high temperatures and solvent quantity to be employed, it can be recommended that sulfolane be used with operating temperatures in the vicinity of $60^{\circ} \mathrm{C}$ and a solvent/feed ratio of 3 for the extraction of such BTX hydrocarbons.

\section{Acknowledgement}

The material presented in this paper is based upon research work supported primarily by the Faculty of Engineering of King Abdulaziz University, under Grant No. 05-412. The authors would like to express their appreciation to the administration of Jeddah Oil Refinery, Petromin-Shell Refinery in Al-Jubail and Riyadh Oil Refinery for their invaluable support in providing us with the samples of their refinery platformates.

\section{References}

[1] Alders, L., Liquid-Liquid Extraction, 2nd ed., Elsevier, Amsterdam. The Netherlands (1959).

[2] Brownstein, A.M., U.S. Petrochemicals, Petroleum Pub. Co.. Tulsa, pp. 98-101 (1972).

[3] Kurts, B. and Schmerling, B., Chemistry of Petroleum Hydrocarbons, Vol. 1. Reinhold Publishing Corporation, New York, pp. 56-57 (1959).

[4] Sittig, M., Aromatic Hydrocarbons, Manufacture and Technology, Noyes Data Corp., p. 14 (1976).

[5] Hengstebeck, R.J., Petroleum Processing, McGraw-Hill, New York, pp. 179-182 (1959).

[6] Steiner, H., Introduction to Petroleum Chemicals, Pergamon Press, New York, p. 101 (1961).

[7] Francis, A.W., Critical Solution Temperatures, American Chemical Society, p. 253 (1961).

[8] Waddams, A.L., Chemicals from Petroleum, 2nd ed.. Chemical Publishing Co., New York, p. 165 (1968).

[9] Davis, B.R., The arosorb process - new refining tool. Oil Gas., May 19, p. 112 (1952).

[10] Read, D., Phenol for solvent extraction of aromatics, Petrol. Refiner, 31 (51): 97 (1952).

[11] Thorton, D.P., First Complex Udex "B-T-X" Plant, Pet. Processing, March, p. 384 (1953).

[12] Ratliff, R.A. and Strobel, W.B., Edelenau process, Petrol. Refiner, 34 (9): 129 (1955).

[13] Gester, G.C., Advances in Chemistry, vol. 5, p. 177 (1951).

[14] Staaterman, H.G., Morris, R.C., Stager, R.M. and Pierotti, G.J., Recovery of Aromatics, vol. 4, Chemical Engineering Press, p. 148 (1947).

[15] Jiang, J., Wang, Y. and Pu, C., Analysis of diethylene glycol as solvent in the extractive distillation of mixed alcohols, Nanjing Inst. Chem. Technol. 17 (4): 241 (1988).

[16] Oveckova, J., Graczova, E. and Surovy, J., Effect of addition of diethylene glycol on the extraction characteristics of mixed solvent-n-methyl pyrrolidone. Chemickotechnol, Fak. Slov. Vys. Skoly Techn., Ropa Uhlie, 30 (1): 57-60 (1988).

[17] Preusser, G. and Emmrich, G., Recovery of high-purity aromatics, Chem. Age. India 38 (1): 39-42 (1987). 
[18] Schobber, G., Gamm, R., Rebbe, M., Schaefer, F. and Leschke, M., Process for recovery of benzene and n-paraffin fraction, Petrolchemisches Kombinat, May, p. 5 (1987).

[19] Corning Limited, Operating Manual, Laboratory Division Stone, Staffordshire, ST15 OB6, England, pp. 15-71 (1981).

[20] Müller, E., Process før BTX Separation, Lurgi Khole Und Mineral Öltechnik GmbH, West Germany, pp. 523-9 (1985). 
استخلاص البنـزين والتولوين والزَّيلسين من مصافي المملكة العربيـة السعوديـة

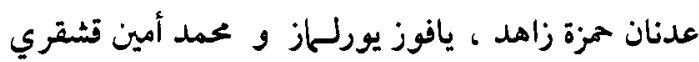

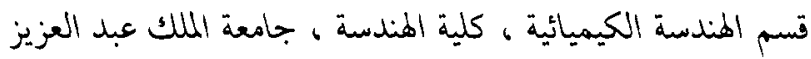

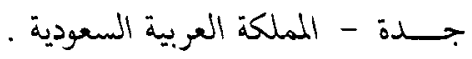

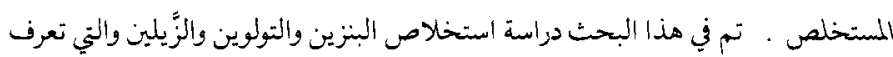

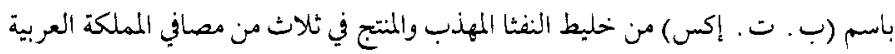

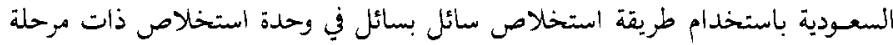

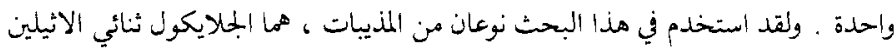

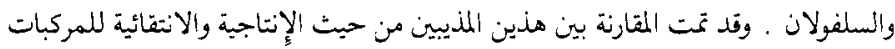

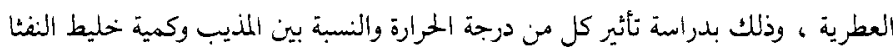

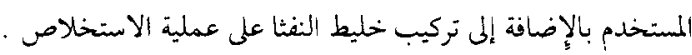

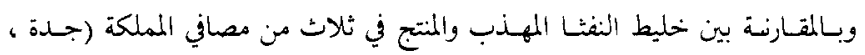

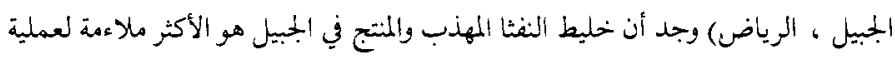

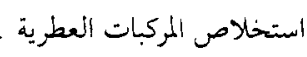

